\title{
In-cell 触控屏用两级预充电柵极驱动电路
}

\author{
沈帅 ${ }^{1,2}$ ，廖聪维 $1^{*} ，$ 杨激文 ${ }^{1}$ ，张盛东 ${ }^{{ }^{*}}$ \\ 1. 北京大学深圳研究生院, 深圳 518055 \\ 2. 深超光电 (深圳) 有限公司, 深圳 518110 \\ * 通信作者. E-mail: zhangsd@pku.edu.cn, liaocw@pku.edu.cn
}

收稿日期: 2020-03-10; 修回日期: 2020-05-13; 接受日期: 2020-06-17; 网络出版日期: 2021-05-08

国家自然科学基金 (批准号: 61774010) 和深圳市科技计划 (批准号: GGFW2017072816344703) 资助项目

\begin{abstract}
摘要 由于触控侦测阶段的保持电荷损失和驱动晶体管的阈值电压漂移, 传统的栅极驱动电路用于 高触控侦测率的内嵌式 (in-cell) 电容触控屏时存在稳定性不佳的问题. 本文提出了一种具有两级预充 电结构的栅极驱动电路, 可有效地减少触控侦测阶段的保持电荷损失量, 并抑制驱动晶体管的阈值电 压漂移. 仿真结果表明, 传统䣂极驱动电路和新栅极驱动电路的邻近级输出波形延迟时间的差异分别 是 $9.3 \%$ 和 $1.6 \%$. 在关键晶体管的阈值电压正向漂移 $10 \mathrm{~V}$ 后, 传统栅极驱动电路和新栅极驱动电路 输出波形延迟时间的增加比率分别为 $120 \%$ 和 $2.4 \%$. 因此, 本文提出的新型栅极驱动电路具有较好的 稳定性, 适用于高触控侦测率的 in-cell 电容触控屏.
\end{abstract}

关键词内嵌式电容触控屏, 栅极驱动电路, 稳定性, 氢化非晶硅, 薄膜晶体管, 时分驱动

\section{1 引言}

近些年, 电容触控屏被广泛地应用到移动电子设备中. 新型的内嵌式 (in-cell) 电容触控屏集成度 高, 模组更轻薄, 穿透率更高, 因此适用于中小尺寸的薄膜晶体管 - 液晶显示器 (TFT-LCD) ${ }^{[1 \sim 5]}$. 然 而, 对于 in-cell 电容触控显示屏, 由于距离较近, 触控信号线和显示信号线之间较大的耦合电容会引 起串扰, 所以通常采用时分驱动方法 (TDDM, time division driving method) 来抑制显示信号和触控信 号之间的相互串扰、提高触控侦测的信噪比 ${ }^{[4,5]}$. TDDM 又分为垂直同步扫描模式和水平同步扫描模 式. 垂直同步扫描模式是先连续完成一帧显示扫描, 之后再利用空白时间进行触控侦测, 该方法中, 触 控侦测频率和显示刷新频率保持一致. 水平同步扫描模式是将触控侦测时间插入在一帧显示扫描时间 内, 即先完成部分的显示扫描, 然后暂停以进行触控侦测, 后续是显示扫描/触控侦测的多次循环 $[4,5]$. 水平同步扫描模式可以在不改变显示刷新频率的情况下, 灵活地调整触控侦测频率. 当触控侦测频率

\footnotetext{
引用格式: 沈帅, 廖聪维, 杨激文, 等. In-cell 触控屏用两级预充电栅极驱动电路. 中国科学: 信息科学, 2021, 51: 1030-1040, doi: 10.1360/SSI-2020-0049

Shen S, Liao C W, Yang J W, et al. A gate driver circuit with two-stage pre-charge structure for in-cell touch panels (in Chinese). Sci Sin Inform, 2021, 51: 1030-1040, doi: 10.1360/SSI-2020-0049
} 


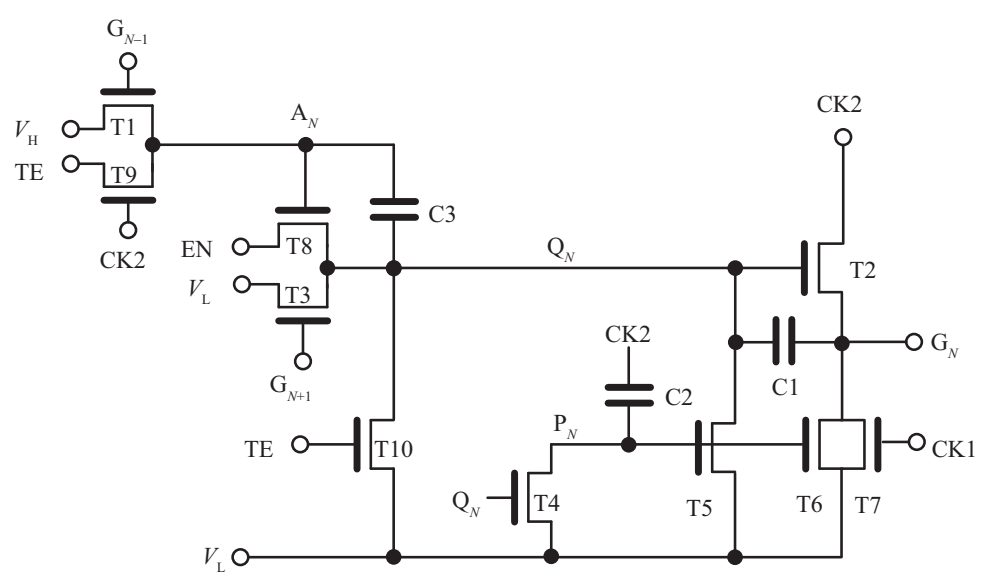

图 1 新电路的单元电路图

Figure 1 A single stage of the proposed gate driver circuit

高于显示扫描频率时, 触控灵敏度可以得到有效的提升. 因此, 对于高触控侦测率的 in-cell 触控屏, 水 平同步扫描模式是主流的驱动方法.

在中小尺寸 TFT-LCD 中, 集成栅极驱动电路 (gate on array, GOA) 已得到广泛应用, 这是因为 GOA 电路有利于减少栅极驱动 IC 及其连接线, 从而可实现窄 (无) 边框显示、简化显示模组制程、降 低显示器的成本 ${ }^{[6 \sim 10]}$. 迄今, in-cell 触控屏的 GOA 电路技术尚不成熟. 对于采用水平同步扫描模式 的 in-cell 触控屏, 在一帧显示时间内需要多次暂停显示扫描进行触控侦测, 因此 GOA 电路需要在不 同位置暂停工作, 于是在触控侦测阶段, “再启动电荷” 应该被存储在 GOA 电路的某个节点. 传统的

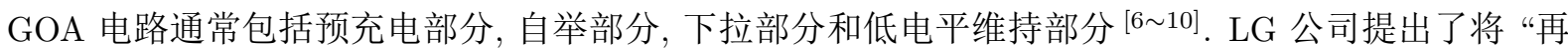
启动电荷” 存储于自举部分的驱动晶体管栅极的方法 [5]. 该方法具有结构简洁的优势, 但是触控阶段 存储着电荷的驱动晶体管具有较大的栅源电压差 $\left(V_{\mathrm{GS}}>0\right)$, 这就造成了 $\mathrm{GOA}$ 电路中不同位置的驱动 晶体管的电压应力情况不一致, 导致其阈值电压漂移量不同 ${ }^{[11,12]}$, 最终会产生驱动能力的差异, 造成 显示画面灰阶不均的现象. Lin 等 ${ }^{[13,14]}$ 提出了在两级栅极电路之间插入电荷存储结构来存储 “再启 动电荷”, 以抑制 GOA 电路中不同位置的驱动晶体管的电压应力差异. 但是, 这些插入的电荷存储结 构位于 GOA 电路的特定级之间, 不仅触控侦测频率不可调整, 而且使得版图更复杂.

本文提出了一种集成㮽极驱动电路, 在触控侦测阶段将 “再启动电荷” 存储于新构建的预充电结 构. 该电路中, 各级驱动晶体管的电压应力时间都相同, 减少了 GOA 电路中各驱动级的电学性能差 异. 此外, 在触控侦测阶段, 连接到新预充电结构上的晶体管的源漏压差 $\left(V_{\mathrm{DS}}\right)$ 较小, 从而减少了该时 段的 “再启动电荷” 损失. 本文将详细阐释这种新的 in-cell 触控栅极驱动电路的原理, 并证明该电路 具有高稳定性.

\section{2 新电路的工作原理}

图 1 是新集成栅极驱动电路的单元电路图. 单元电路由预充电部分、自举部分、下拉部分和低电 平维持这 4 个部分组成. 预充电部分包括 $\mathrm{T} 1, \mathrm{~T} 8$ 和电容 $\mathrm{C} 3$; 自举部分包括驱动晶体管 $\mathrm{T} 2$ 和电容 $\mathrm{C} 1$; 下拉部分包括 $\mathrm{T} 3, \mathrm{~T} 4, \mathrm{~T} 9$ 和 $\mathrm{T} 10$; 低电平维持部分则包括 $\mathrm{T} 5, \mathrm{~T} 6, \mathrm{~T} 7$ 和电容 $\mathrm{C} 2$. 传统 $\mathrm{GOA}$ 电路的 单元电路通常只有一个预充电节点 $\mathrm{Q}_{N}$, 连接至驱动晶体管 $\mathrm{T} 2$ 的栅极 ${ }^{[6 \sim 10]}$, 而新电路具有两级预充 


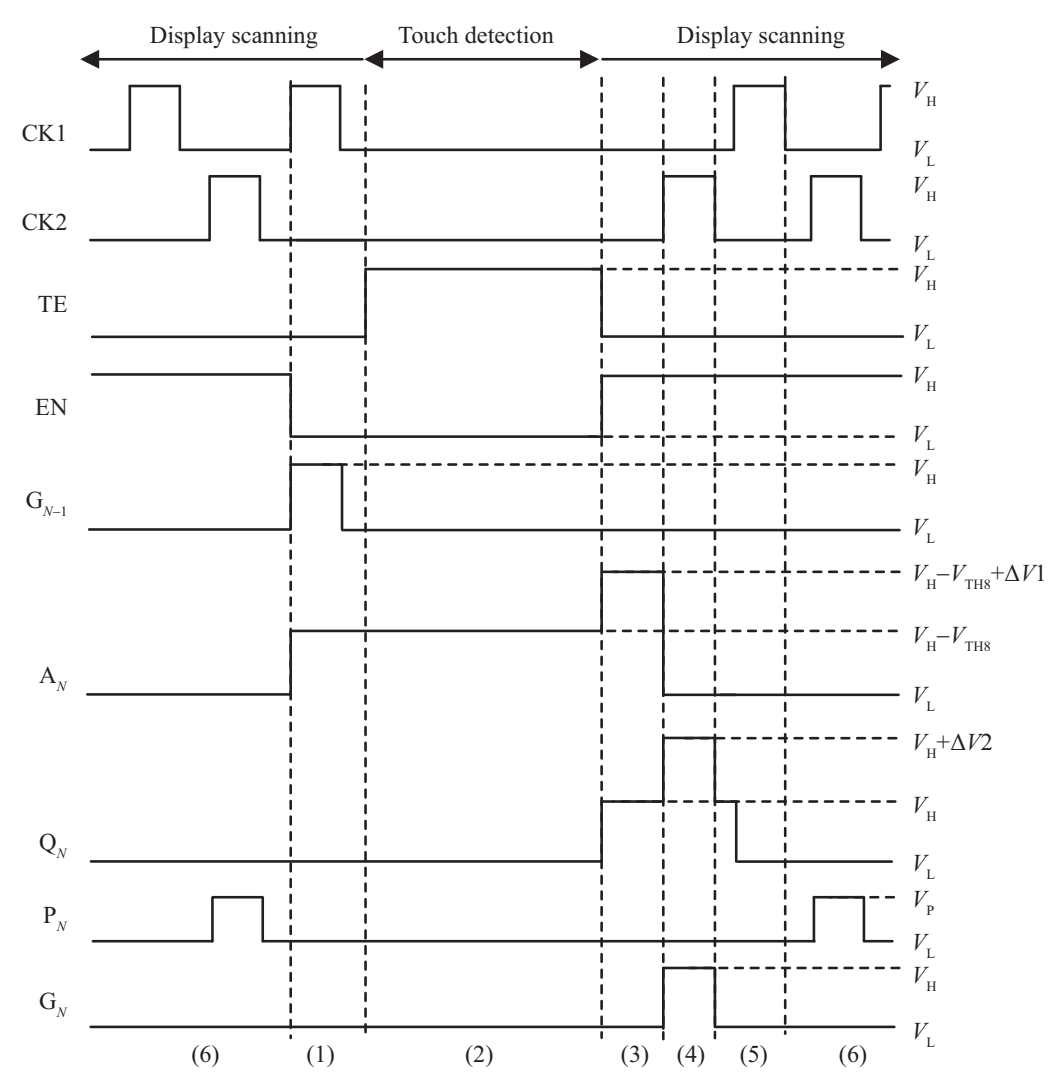

图 2 新电路的时序图

Figure 2 The timing diagram of the proposed gate driver circuit

电结构, 包括新引入的第 1 预充电节点 $\mathrm{A}_{N}$ 以及第 2 预充电节点 $\mathrm{Q}_{N}$. 第 1 级预充电结构的 $\mathrm{T} 1$ 给节 点 $\mathrm{A}_{N}$ 充电, 并由 $\mathrm{C} 3$ 存储电荷; 第 2 级预充电结构的 $\mathrm{T} 8$ 再给节点 $\mathrm{Q}_{N}$ 充电. 在触控侦测阶段, “再启 动电荷” 存储在节点 $\mathrm{A}_{N}$. 每一级单元电路的控制信号包括 2 个时钟信号 CK1 和 CK2, 2 个触控使能 信号 $\mathrm{TE}$ 和 $\mathrm{EN}$, 以及高压电源 $V_{\mathrm{H}}$ 和低压电源 $V_{\mathrm{L}}$.

新电路的工作时序如图 2 所示, 共为如下 6 个阶段:

(1) 第 1 级预充电阶段. 由于 $\mathrm{GOA}$ 电路中第 $N-1$ 级的输出 $\mathrm{G}_{N-1}$ 为高电平 $V_{\mathrm{H}}, \mathrm{T} 1$ 被打开, 节 点 $\mathrm{A}_{N}$ 被充电上拉到 $V_{\mathrm{H}}-V_{\mathrm{TH} 1}$. 因此, 晶体管 $\mathrm{T} 8$ 被打开 $\left(V_{\mathrm{GS} 8}>V_{\mathrm{TH} 8}\right)$. 这个阶段 $\mathrm{EN}$ 为低电平 $V_{\mathrm{L}}$, 所以第 2 级预充电结构的输出节点 $\mathrm{Q}_{N}$ 保持着低电平 $V_{\mathrm{L}}$, 驱动晶体管 $\mathrm{T} 2$ 处于关断状态. 故在阶段 (1), 第 1 级预充电结构被触发, 第 2 级预充电及输出结构均处于非使能状态.

(2) 触控侦测阶段. 触控侦测开始后, 控制信号 $\mathrm{TE}$ 变为高电平 $V_{\mathrm{H}}$, 于是 $\mathrm{T} 10$ 被打开, 且各级栅极 驱动电路的 $\mathrm{Q}$ 节点被下拉到低电平 $V_{\mathrm{L}}$. 由于 $\mathrm{G}_{N-1}$ 变为低电平 $V_{\mathrm{L}}, \mathrm{T} 1$ 被关闭; “再启动电荷” 被存 储在 $\mathrm{C} 3$ 电容. 在阶段 $(2), V_{\mathrm{H}}$ 和 $\mathrm{TE}$ 都是高电平, 因此与节点 $\mathrm{A}_{N}$ 相连的晶体管 $\mathrm{T} 1$ 和 $\mathrm{T} 9$ 均具有较 小的源漏电压差, 这有利于抑制电容 $\mathrm{C} 3$ 的电荷损失.

(3) 第 2 级预充电阶段. 触控侦测结束后, 控制信号 TE 变为低电平 $V_{\mathrm{L}}$, 且 $\mathrm{EN}$ 信号变为高电平 $V_{\mathrm{H}}$. 由于节点 $\mathrm{A}_{N}$ 为悬浮状态, 其电位通过电容自举被抬升为 $V_{\mathrm{AN} \_b o o t}=V_{\mathrm{H}}-V_{\mathrm{TH} 1}+\Delta V 1$. 根据电 
荷守恒关系, 可以推导得到 $\Delta V 1$ 为

$$
\Delta V 1=\frac{\left(C_{\mathrm{C} 3}+C_{\mathrm{GS} 8}+C_{\mathrm{GD} 8}\right) \times\left(V_{\mathrm{H}}-V_{\mathrm{L}}\right)}{C_{\mathrm{AN} \_a l l}},
$$

其中, $C_{\mathrm{AN} \_ \text {all }}$ 是连接到节点 $\mathrm{A}_{N}$ 的总电容. $C_{\mathrm{AN} \_a l l}=C_{\mathrm{C} 3}+C_{\mathrm{GS} 1}+C_{\mathrm{GS} 8}+C_{\mathrm{GD} 8}+C_{\mathrm{GS} 9}$. 晶体管 $\mathrm{T} 8$ 被 充分打开, 节点 $\mathrm{Q}_{N}$ 通过第 2 级预充电结构被快速地上拉到 $V_{\mathrm{H}}$. 于是, 晶体管 $\mathrm{T} 4$ 被打开, 节点 $\mathrm{P}_{N}$ 被拉低至 $V_{\mathrm{L}}$. 在阶段 (3), “再启动电荷” 使得节点 $\mathrm{Q}_{N}$ 电位抬升, 显示扫描被重新启动.

(4) 自举阶段. 跟随着 $\mathrm{CK} 2$ 信号变为高电平, 导通着的驱动晶体管 $\mathrm{T} 2$ 输出充电电流将 $\mathrm{G}_{N}$ 上拉 至高电平; 另一方面, 由于电容自举效应, 节点 $\mathrm{Q}_{N}$ 的电压被抬举到 $V_{\mathrm{H}}+\Delta V 2$. 根据电荷守恒关系, 可 以推导得到 $\Delta V 2$ 为

$$
\Delta V 2=\frac{\left(C_{\mathrm{C} 1}+C_{\mathrm{GS} 2}+C_{\mathrm{GD} 2}\right) \times\left(V_{\mathrm{H}}-V_{\mathrm{L}}\right)-\left(C_{\mathrm{C} 3}+C_{\mathrm{GS} 8}\right) \times\left(V_{\mathrm{AN} \_b o o t}-V_{\mathrm{L}}\right)}{C_{\mathrm{QN} \_a l l}},
$$

其中, $C_{\mathrm{QN} \_ \text {all }}$ 是连接到节点 $\mathrm{Q}_{N}$ 的总电容. $C_{\mathrm{QN} \_a l l}=C_{\mathrm{C} 1}+C_{\mathrm{C} 3}+C_{\mathrm{GS} 2}+C_{\mathrm{GD} 2}+C_{\mathrm{GD} 3}+C_{\mathrm{GS} 4}+C_{\mathrm{GD} 4}+$ $C_{\mathrm{GD} 5}+C_{\mathrm{GS} 8}+C_{\mathrm{GD} 10}$. 在自举阶段, 驱动晶体管 $\mathrm{T} 2$ 持续保持着较强的驱动能力. 在此阶段, 节点 $\mathrm{P}_{N}$ 维持着低电平 $V_{\mathrm{L}}$; 并且晶体管 $\mathrm{T} 9$ 被打开 (CK2 为高电平), 节点 $\mathrm{A}_{N}$ 被拉低到低电平 $V_{\mathrm{L}}$.

(5) 下拉阶段. 在自举阶段之后, $\mathrm{CK} 2$ 信号变为低电平 $V_{\mathrm{L}}$, 于是驱动晶体管 $\mathrm{T} 2$ 将 $\mathrm{CK} 2$ 的低电平 $V_{\mathrm{L}}$ 传输至输出 $\mathrm{G}_{N}$, 悬浮节点 $\mathrm{Q}_{N}$ 电位也下降到 $V_{\mathrm{H}}$. 随后, GOA 电路中第 $N+1$ 级的输出 $\mathrm{G}_{N+1}$ 和 $\mathrm{CK} 1$ 信号变为高电平 $V_{\mathrm{H}}$, 晶体管 $\mathrm{T} 3$ 和 $\mathrm{T} 7$ 被打开, 分别下拉节点 $\mathrm{Q}_{N}$ 及 $\mathrm{G}_{N}$ 的电位.

(6) 低电平维持阶段. 在非选通阶段, 第 $N$ 级电路的输出 $\mathrm{G}_{N}$ 应该维持低电平. 但是时钟馈通效 应可能引起节点 $\mathrm{Q}_{N}$ 和 $\mathrm{G}_{N}$ 上的电荷积累. 为了抑制电荷积累, 当 $\mathrm{CK} 2$ 跳变为高电平 $V_{\mathrm{H}}$ 时, 节点 $\mathrm{P}_{N}$ 的电压通过 $\mathrm{C} 2$ 被耦合至 $V_{\mathrm{P}}$, 晶体管 $\mathrm{T} 5$ 和 $\mathrm{T} 6$ 被打开, 分别使节点 $\mathrm{Q}_{N}$ 和 $\mathrm{G}_{N}$ 维持在低电平 $V_{\mathrm{L}}$. 另一方面, 当 $\mathrm{CK} 1$ 跳变为高电平 $V_{\mathrm{H}}$ 时, 输出节点 $\mathrm{G}_{N}$ 则通过 $\mathrm{T} 7$ 保持低电平 $V_{\mathrm{L}}$. 因此, 在整个低电 平维持阶段, 时钟馈通效应都被较好地抑制, 输出 $\mathrm{G}_{N}$ 一直被维持在低电平 $V_{\mathrm{L}}$.

综上所述, 这种新的栅极驱动电路具有两个优点: (1) 在触控侦测阶段, 栅极驱动电路各级的 $\mathrm{Q}$ 节 点均维持于低电平 $V_{\mathrm{L}}$, 可抑制不同级驱动晶体管的阈值电压漂移差异; (2) 可减少存储在第 1 级预充 电节点 $\mathrm{A}_{N}$ 的电荷损失量, 有利于减小邻近级输出波形的差异.

\section{3 结果与讨论}

本文采用 Eldo 软件来验证新栅极驱动电路的功能, 并重点分析电路的稳定性. 根据实际制备得 到的 a-Si:H TFT, 采用半导体测试仪 Agilent B1500A 测试了器件的转移特性, 并校准了器件的模型参 数 $(\mathrm{RPI}$ model Level $=64)$ 以用于电路的 SPICE 仿真. 图 3 是一个使用标准五道掩模制作的 a-Si:H TFT 在 $V_{\mathrm{DS}}=0.5 \mathrm{~V}$ 和 $V_{\mathrm{DS}}=10 \mathrm{~V}$ 时量测和拟合得到的特性转移曲线. 此 a-Si:H TFT 的栅介质层 厚度为 $400 \mathrm{~nm}, \mathrm{a}-\mathrm{Si}: \mathrm{H}$ 膜厚 $130 \mathrm{~nm}, \mathrm{n}^{+} \mathrm{a}-\mathrm{Si}: \mathrm{H}$ 膜厚 $30 \mathrm{~nm}$. 器件的 $\mathrm{W} / \mathrm{L}=2500 \mu \mathrm{m} / 3.8 \mu \mathrm{m}$, 阈值电 压为 $1.98 \mathrm{~V}$, 有效场效应迁移率为 $0.37 \mathrm{~cm}^{2}(\mathrm{~V} \cdot \mathrm{s})^{-1}$. 对于解析度为 $1520(\mathrm{H}) \times 720(\mathrm{~V}) \times \mathrm{RGB}$ 的 5.99 in $\mathrm{HD}+$ 非晶硅 in-cell 显示器产品, 各条栅极驱动线的负载电阻 $R_{\mathrm{L}}$ 为 $1.3 \mathrm{k} \Omega$, 负载电容 $C_{\mathrm{L}}$ 为 $65 \mathrm{pF}$. 表 1 列出了新电路的设计参数.

图 4 示意了新栅极驱动电路在触控侦测前后的瞬态响应. 时钟信号 CK1 和 CK2 之间的时间间隙 为 $5 \mu \mathrm{s}$, 触控侦测的时长为 $200 \mu \mathrm{s}$. 在触控侦测期间 (2), 节点 $\mathrm{A}_{N}$ 的电压保持为 $15.2 \mathrm{~V}$, 几乎没有损 失. 在第 2 次预充电阶段 (3), 节点 $\mathrm{A}_{N}$ 的电压被自举到 $35.2 \mathrm{~V}$ (根据式 (1) 的推算, 自举电压约 $36.5 \mathrm{~V}$. 


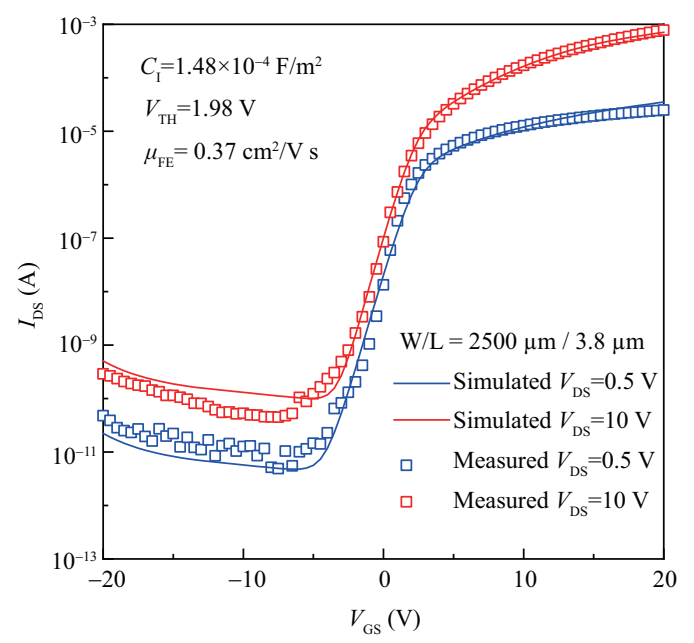

图 3 (网络版彩图) 量测及拟合的 $\mathrm{W} / \mathrm{L}=\mathbf{2 5 0 0 \mu \mathrm { m } /}$ $3.8 \mu \mathrm{m}$ a-Si:H TFT 的特性转移曲线

Figure 3 (Color online) Measured and simulated transfer characteristics of an a-Si:H TFT with $\mathrm{W} / \mathrm{L}=2500 \mu \mathrm{m} /$ $3.8 \mu \mathrm{m}$

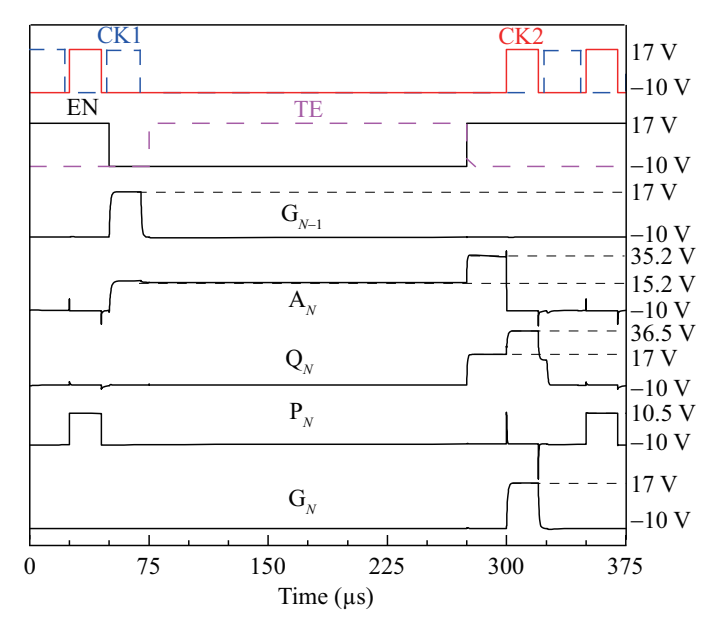

图 4 (网络版彩图) 新栅极驱动电路的瞬态响应的模拟 结果

Figure 4 (Color online) The simulated transient response of the proposed gate driver circuit

表 1 新电路相关设计参数

Table 1 Parameters of the proposed gate driver circuit

\begin{tabular}{cccc}
\hline Parameter & Value & Parameter & Value \\
\hline$W_{\mathrm{T} 1, \mathrm{~T} 3, \mathrm{~T} 7, \mathrm{~T} 8, \mathrm{~T} 9}(\mu \mathrm{m})$ & 250 & $W_{\mathrm{T} 2}(\mu \mathrm{m})$ & 2500 \\
$W_{\mathrm{T} 4, \mathrm{~T} 5, \mathrm{~T} 10}(\mu \mathrm{m})$ & 100 & $W_{\mathrm{T} 6}(\mu \mathrm{m})$ & 200 \\
Channel length $(\mu \mathrm{m})$ & 3.8 & $C_{\mathrm{C} 1}(\mathrm{pF})$ & 1 \\
CK pulse width $(\mu \mathrm{s})$ & 20 & $C_{\mathrm{C} 2}(\mathrm{pF})$ & 1.5 \\
Touch sensing period $(\mu \mathrm{s})$ & 200 & $C_{\mathrm{C} 3}(\mathrm{pF})$ & 0.1 \\
$V_{\mathrm{H}}(\mathrm{V})$ & 17 & $V_{\mathrm{L}}(\mathrm{V})$ & -10 \\
\hline
\end{tabular}

推算值与模拟值之间的误差主要是晶体管 $\mathrm{T} 9$ 的泄漏电流等影响因素对节点 $\mathrm{A}_{N}$ 的自举过程造成了 影响, 但总体上二者的结果较为相符). 节点 $\mathrm{Q}_{N}$ 被预充电到 $17 \mathrm{~V}$. 在自举阶段 (4), 节点 $\mathrm{Q}_{N}$ 的电压被 自举到 $36.5 \mathrm{~V}$ (根据式 (2) 的计算, 此阶段节点 $\mathrm{Q}_{N}$ 的自举电压约 $39.9 \mathrm{~V}$. 仿真分析表明, 在节点 $\mathrm{Q}_{N}$ 自举过程中节点 $\mathrm{P}_{N}$ 有被 $\mathrm{C} 2$ 耦合产生瞬态噪声电压, $\mathrm{P}_{N}$ 控制的晶体管 $\mathrm{T} 5$ 的瞬态漏电过程削弱了节 点 $\mathrm{Q}_{N}$ 的自举电压, 因此其模拟值比计算值偏小). 输出节点 $\mathrm{G}_{N}$ 被满幅度地充电到 $17 \mathrm{~V}$. 该分析结果 表明, “再启动电荷” 在触控侦测阶段几乎没有损失. 并且节点 $\mathrm{Q}_{N}$ 在触控侦测阶段 (2) 保持在 $-10 \mathrm{~V}$, $\mathrm{T} 2$ 没有受电压应力. 在触控侦测结束后, 栅极驱动电路能返回正常的显示扫描状态.

图 5 是新集成栅极电路的级联框图及驱动时序, 栅极电路共驱动 1520 行. 左侧的栅极电路驱动 760 级奇数显示行, 右侧的栅极电路驱动 760 级偶数显示行. 图 5(b) 示意了奇数级电路和偶数级电路 的时钟控制信号. 图 6 示意了单级栅极驱动电路的版图设计, 其版图面积为 $625 \mu \mathrm{m} \times 181.2 \mu \mathrm{m}$. 其中 新增的预充电结构及其信号线占用面积 $130 \mu \mathrm{m} \times 181.2 \mu \mathrm{m}$. 该版图根据标准的五道掩模制程设计, 考 虑了制程能力以及可能的套刻误差等因素, 版图设计符合产业界的量产规格. 在考虑了信号线和玻璃 


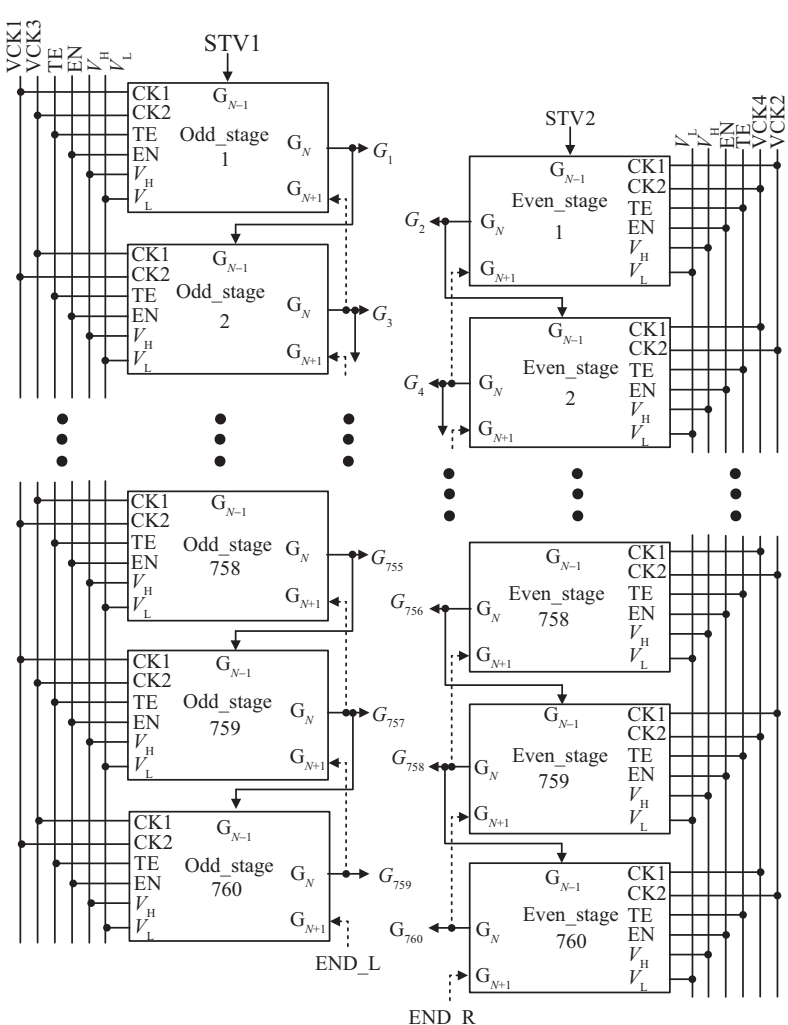

(a)

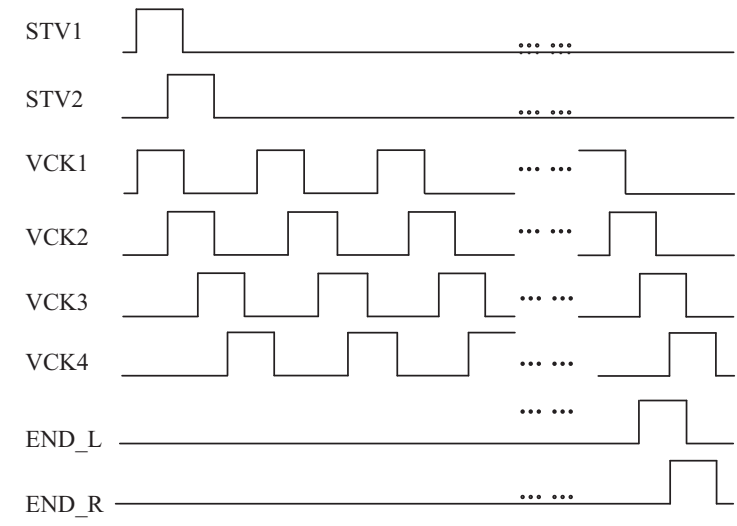

(b)

图 5 用于 5.99 in $\mathrm{HD}+$ in-cell 显示屏的新电路级联框图及驱动时序

Figure 55.99 in HD+ in-cell panel with the proposed gate driver circuit: (a) the system diagram; (b) driving clock signals

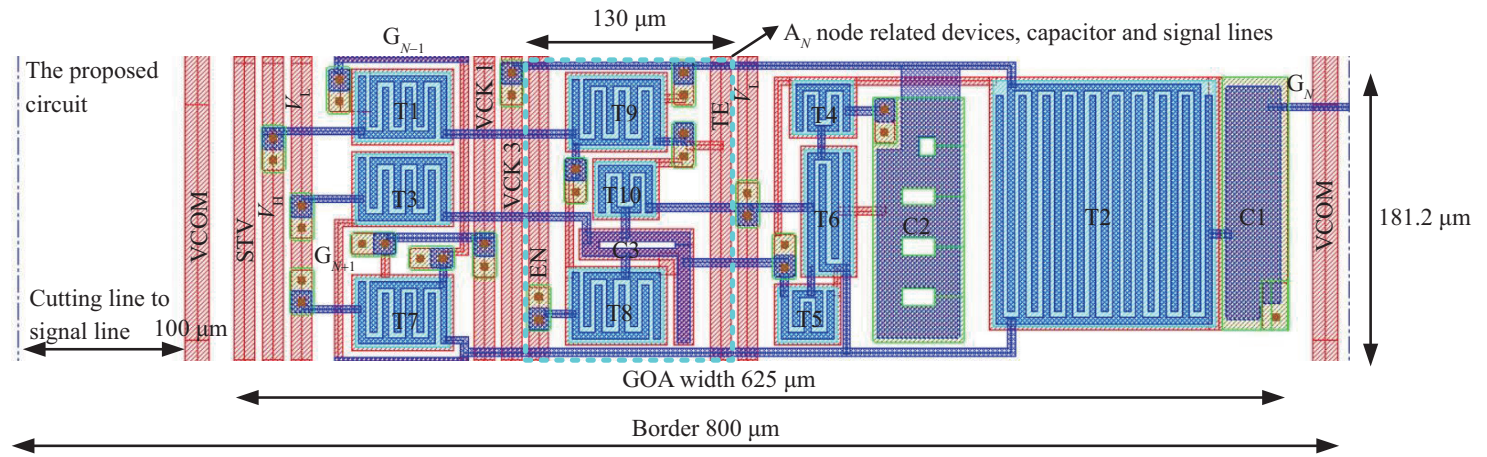

图 6 (网络版彩图) 单级新栅极驱动电路的版图设计

Figure 6 (Color online) A single stage layout of the proposed circuit

切割裕量等因素后, 新电路应用于 $5.99 \mathrm{in} \mathrm{HD}+\mathrm{in}-\mathrm{cell}$ 显示屏时可实现 $800 \mu \mathrm{m}$ 的左右边框.

图 7 示意了水平同步扫描模式的 in-cell 显示屏的工作时序. 在一帧时间内显示扫描被分为多 份, 在触控侦测时, 显示扫描被暂停, “再启动电荷” 存储在某级栅极电路中. 表 2 对比了在一帧时间 $(16.67 \mathrm{~ms})$ 中传统栅极驱动电路和新电路的关键晶体管开启时受电压偏置的时间占比. 图 8 示意了传 统电路 ${ }^{[9]}$ 和新电路的第 $N$ 级单元电路中的关键晶体管. 对于传统电路, 显示扫描暂停时若 “再启动 


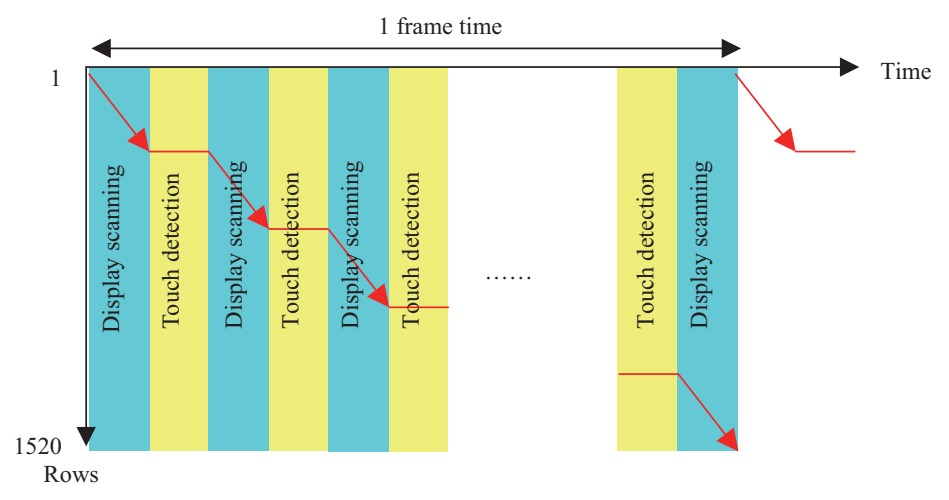

图 7 (网络版彩图) 在 1 帧时间内显示和触控的时序图

Figure 7 (Color online) Timing diagram for display scanning and touch detection in 1 frame time

表 2 电路关键晶体管受电压偏置时间占比

Table 2 Duty ratio comparison of key TFTs in the circuit

\begin{tabular}{cccc}
\hline Key TFTs & \multicolumn{3}{c}{ Stages } \\
\cline { 2 - 3 } & $(N-1)$ th $(\%)$ & $N$ th $(\%)$ & $(N+1)$ th $(\%)$ \\
\hline T2 in the conventional circuit & 1.50 & 1.50 & 0.30 \\
T8 in the proposed circuit & 0.12 & 1.47 & 0.12 \\
T2 in the proposed circuit & 0.30 & 0.30 & 0.30 \\
\hline
\end{tabular}

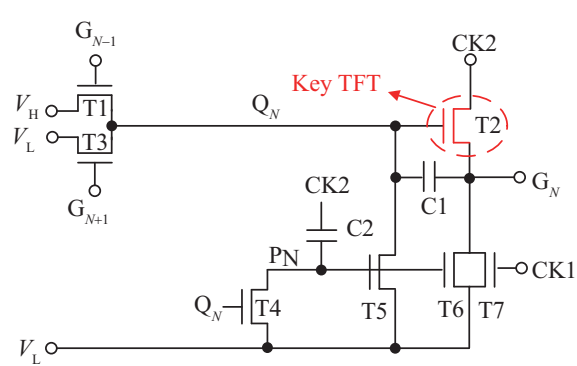

(a)

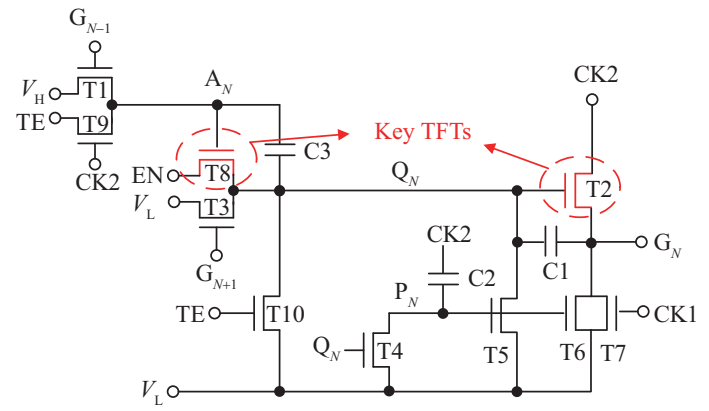

(b)

图 8 (网络版彩图) (a) 传统栅极电路 ${ }^{[9]}$ 和 (b) 新栅极电路中的关键晶体管

Figure 8 (Color online) The key TFTs in gate driver circuits: (a) a conventional gate driver circuit ${ }^{[9]}$; (b) the proposed circuit

电荷” 存储在第 $N$ 级驱动晶体管 $\mathrm{T} 2$ 的栅极节点 $\mathrm{Q}_{N}$, 则第 $N$ 级和第 $N+1$ 级的驱动晶体管 $\mathrm{T} 2$ 的 电压偏置时间会存在差异, 会造成邻近两级 $\mathrm{T} 2$ 晶体管的阈值电压漂移不同. 而新电路在触控侦测过 程中将 “再启动电荷” 存储在第 $N$ 级晶体管 $\mathrm{T} 8$ 的栅极节点 $\mathrm{A}_{N}$, 所以新电路各级驱动晶体管 $\mathrm{T} 2$ 电 压偏置时间都相同, 但是第 $N$ 级与第 $N-1$ 级和第 $N+1$ 级的晶体管 $\mathrm{T} 8$ 存在电压偏置时间差异, 也 会引起阈值电压漂移的差异. 因此, 为了验证新电路的稳定性, 模拟对比了传统电路关键晶体管 $\mathrm{T} 2$ 及 新电路关键晶体管 $\mathrm{T} 8$ 在阈值电压正向漂移 $10 \mathrm{~V}$ 前后, 驱动晶体管的栅极节点 $\mathrm{Q}_{N}$ 及输出 $\mathrm{G}_{N}$ 电压 波形的差异.

图 9 示意了在驱动晶体管 $\mathrm{T} 2$ 阈值电压正向漂移 $10 \mathrm{~V}$ 前后, 传统电路的 $\mathrm{Q}_{N}$ 和 $\mathrm{G}_{N}$ 的电压波形. 

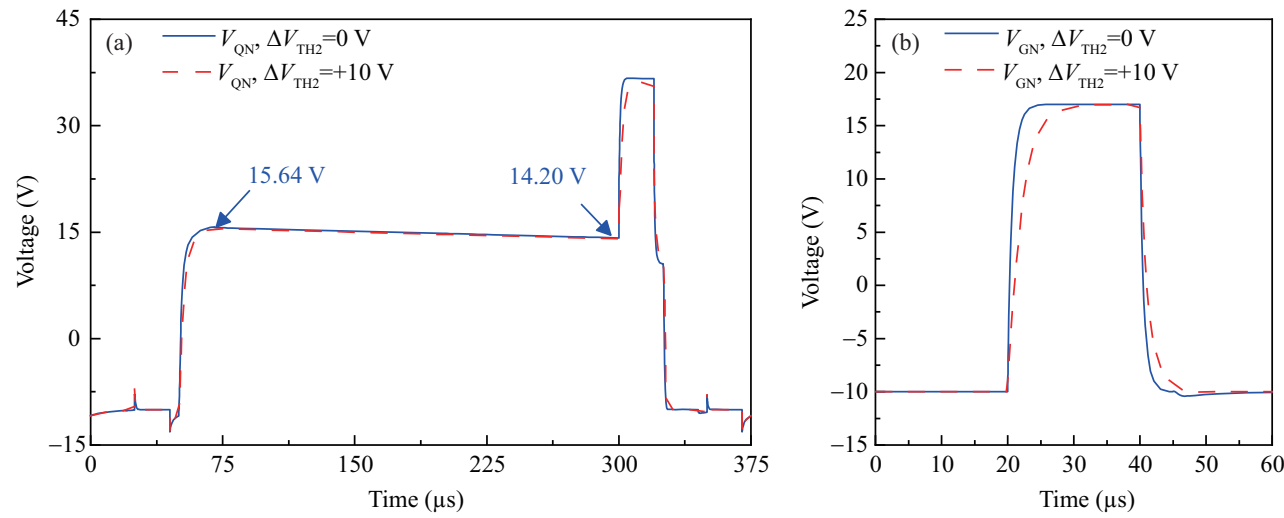

图 9 (网络版彩图) 关键 TFT T2 特性漂移对传统栅极驱动电路瞬态响应的影响

Figure 9 (Color online) Effect of $V_{\mathrm{TH}}$ shift of key TFT T2 on the transient response of the conventional gate driver circuit. (a) Simulated $\mathrm{Q}_{N}$ when $V_{\mathrm{TH} 2}$ shifts by $0 \mathrm{~V}$ or $+10 \mathrm{~V}$; (b) simulated the $\mathrm{G}_{N}$ when $V_{\mathrm{TH} 2}$ shifts by $0 \mathrm{~V}$ or $+10 \mathrm{~V}$

表 3 传统栅极驱动电路输出 $\mathrm{G}_{N}$ 和 $\mathrm{G}_{N+1}$ 的上升和下降时间比较

Table 3 Comparison of rising and falling time of $\mathrm{G}_{N}$ and $\mathrm{G}_{N+1}$ in the conventional circuit

\begin{tabular}{ccc}
\hline Outputs & \multicolumn{3}{c}{ Delay time } \\
\cline { 2 - 3 } & Rising time $(\mu \mathrm{s})$ & Falling time $(\mu \mathrm{s})$ \\
\hline $\mathrm{G}_{N}\left(V_{\mathrm{TH} 2}=0 \mathrm{~V}\right)$ & 1.72 & 1.41 \\
$\mathrm{G}_{N}\left(V_{\mathrm{TH} 2}=+10 \mathrm{~V}\right)$ & 5.33 & 3.11 \\
$\mathrm{G}_{N+1}\left(V_{\mathrm{TH} 2}=0 \mathrm{~V}\right)$ & 1.54 & 1.29 \\
\hline
\end{tabular}

在触控侦测阶段, 节点 $\mathrm{Q}_{N}$ 的电压会损失 $1.44 \mathrm{~V}$, 并且驱动晶体管 $\mathrm{T} 2$ 受电压应力; 如图 9(b) 所示, 在 $\mathrm{T} 2$ 的阈值电压漂移后, 输出波形 $\mathrm{G}_{N}$ 出现较严重变形. 表 3 对比了传统电路输出 $\mathrm{G}_{N}$ 和 $\mathrm{G}_{N+1}$ 的上 升和下降时间. 在 $\mathrm{T} 2$ 的阈值电压漂移前, 由于存储电荷的损失, 输出 $\mathrm{G}_{N}$ 和 $\mathrm{G}_{N+1}$ 上升时间和下降时 间分别存在 $11.7 \%$ 和 $9.3 \%$ 的差异. 在 $\mathrm{T} 2$ 的阈值电压正向漂移 $10 \mathrm{~V}$ 后, 输出 $\mathrm{G}_{N}$ 的上升时间和下降 时间分别增加了 $209.9 \%$ 和 $120.6 \%$. 因此, 传统电路确实存在这两个问题: (1) 存储在节点 $\mathrm{Q}_{N}$ 的“再 重启电荷”由于泄漏电流而损失, 造成相邻级栅极驱动的输出波形差异量大; (2) 由于晶体管 $\mathrm{T} 2$ 的阈 值电压漂移差异, 不同级的栅极驱动电路的驱动能力存在较明显差异, 可能造成显示图像不均匀.

图 10 示意了在 $\mathrm{T} 8$ 阈值电压正向漂移 $10 \mathrm{~V}$ 前后, 新栅极驱动电路的 $\mathrm{Q}_{N}$ 和 $\mathrm{G}_{N}$ 的电压波形. 节 点 $\mathrm{Q}_{N}$ 在触控侦测前和触控侦测阶段均保持在 $-10 \mathrm{~V}$, 驱动晶体管 $\mathrm{T} 2$ 没有受电压应力; 如图 $10(\mathrm{~b})$ 所示, 在 $\mathrm{T} 8$ 的阈值电压漂移前后, 输出波形 $\mathrm{G}_{N}$ 几乎没有变化. 表 4 对比了新电路输出 $\mathrm{G}_{N}$ 和 $\mathrm{G}_{N+1}$ 的上升和下降时间. 在 $\mathrm{T} 8$ 阈值电压漂移前, 输出 $\mathrm{G}_{N}$ 和 $\mathrm{G}_{N+1}$ 上升时间和下降时间的差异量分别为 $1.3 \%$ 和 $1.6 \%$. 在 $\mathrm{T} 8$ 阈值电压正向漂移, 即阈值电压增加 $10 \mathrm{~V}$ 后, 输出 $\mathrm{G}_{N}$ 的上升时间和下降时间 仅分别变化了 $2.0 \%$ 和 $2.4 \%$. 图 10 和表 4 的结果证明: (1) 新栅极驱动电路中, 相邻级栅极驱动的输 出波形差异量小; (2) 关键 TFT (这里为 $\mathrm{T} 8$, 其电压应力时间最长) 的阈值电压漂移几乎不会影响第 2 级预充电节点 $\mathrm{Q}_{N}$ 的电压和输出波形. 以上对比结果表明, 新栅极驱动电路具有较好的稳定性.

表 5 对比了参考文献和本文提出的栅极驱动电路的性能. 对于传统的 $7 \mathrm{~T} 2 \mathrm{C}$ 电路, 由于 “再启动 电荷” 在触控侦测阶段被存储在驱动晶体管的栅极, 不同显示行的驱动晶体管电压应力时间长短不均. 文献 [14] 的方案在指定的栅极驱动电路级之间增加了 $3 \mathrm{~T} 1 \mathrm{C}$ 结构用于存储 “再启动电荷”, 虽然该栅 极驱动电路抑制了不同位置驱动晶体管电压应力不均匀性, 但是版图设计的复杂度较高, 并且触控帧 

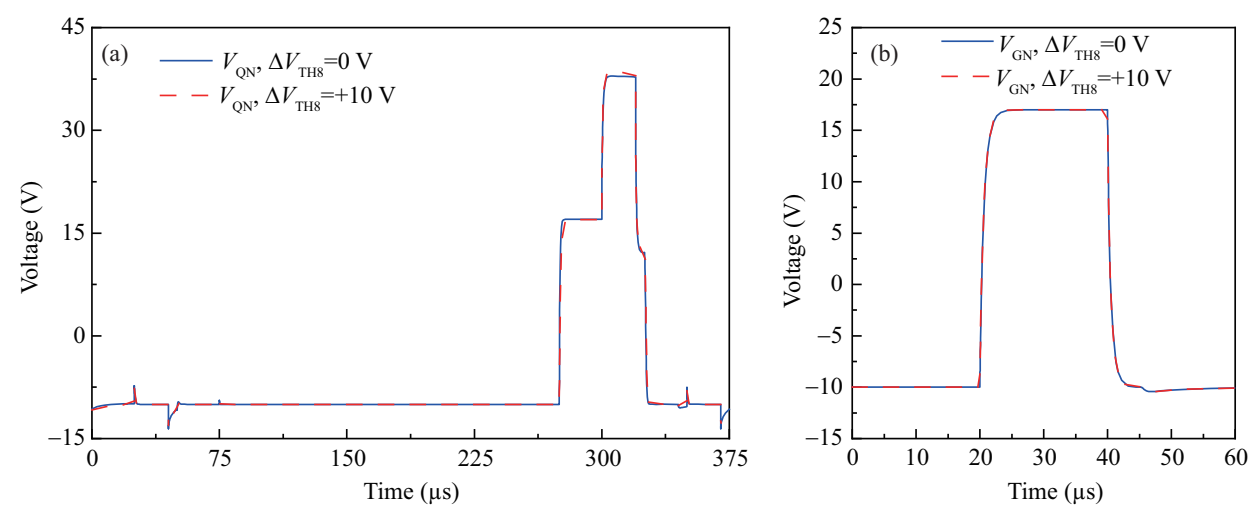

图 10 (网络版彩图) 关键 TFT T8 特性漂移对新柪极驱动电路瞬态响应的影响

Figure 10 (Color online) Effect of $V_{\mathrm{TH}}$ shift of key TFT T8 on the transient response of the proposed gate driver circuit. (a) Simulated $\mathrm{Q}_{N}$ when $V_{\mathrm{TH} 8}$ shifts by $0 \mathrm{~V}$ or $+10 \mathrm{~V}$; (b) simulated the $\mathrm{G}_{N}$ when $V_{\mathrm{TH} 8}$ shifts by $0 \mathrm{~V}$ or $+10 \mathrm{~V}$

表 4 新栅极驱动电路 $\mathbf{G}_{N}$ 和 $\mathbf{G}_{N+1}$ 的上升时间和下降时间比较

Table 4 Comparison of rising and falling time of $G_{N}$ and $G_{N+1}$ in the proposed circuit

\begin{tabular}{ccc}
\hline Outputs & \multicolumn{3}{c}{ Delay time } \\
\cline { 2 - 3 } & Rising time $(\mu \mathrm{s})$ & Falling time $(\mu \mathrm{s})$ \\
\hline $\mathrm{G}_{N}\left(V_{\mathrm{TH} 8}=0 \mathrm{~V}\right)$ & 1.53 & 1.28 \\
$\mathrm{G}_{N}\left(V_{\mathrm{TH} 8}=+10 \mathrm{~V}\right)$ & 1.50 & 1.25 \\
$\mathrm{G}_{N+1}\left(V_{\mathrm{TH} 8}=0 \mathrm{~V}\right)$ & 1.51 & 1.26 \\
\hline
\end{tabular}

表 5 新电路及参考文献电路的对比

Table 5 Comparison between the proposed circuit and the reference works

\begin{tabular}{llll}
\hline & The conventional circuit ${ }^{[9]}$ & Reference circuit ${ }^{[14]}$ & The proposed circuit \\
\hline Structure & $7 \mathrm{~T} 2 \mathrm{C}$ & Inserted 3T1C +8T2C & 10T3C \\
Single stage layout area & $495 \mu \mathrm{m} \times 181.2 \mu \mathrm{m}$ & $\mathrm{N} / \mathrm{A}$ & $625 \mu \mathrm{m} \times 181.2 \mu \mathrm{m}$ \\
Control signal lines & 4 & 6 & 6 \\
$\begin{array}{l}\text { Increasing ratio of delay time } \\
\text { after key TFT's V }\end{array}$ & Rising time $209.9 \%$ & Rising time $2.14 \%$ & Rising time $2.0 \%$ \\
Adjustable touch report rate & Falling time $120.6 \%$ & Falling time $1.31 \%$ & Falling time $2.4 \%$ \\
$\begin{array}{l}\text { Duty ratio of driving TFT } \\
\text { for different stages }\end{array}$ & $N$ th $1.5 \%$ & No & Yes \\
\hline
\end{tabular}

率以及时序不可调整.

本论文提出的栅极驱动电路将 “再启动电荷” 存储到两级预充电结构, 不同位置驱动晶体管的电 压应力较小且均匀. 版图设计也相对简单, 版图面积仅比传统电路宽 $130 \mu \mathrm{m}$. 通过信号线的时序控制, 本电路能够灵活地调整显示扫描暂停位置, 从而调整触控侦测频率及触控侦测的起始位置. 新电路具 有很好的稳定性, 即使关键晶体管阈值电压正向漂移 $10 \mathrm{~V}$, 输出波形的延迟时间差异量也小于 $2.4 \%$. 图 11 示意了新栅极驱动电路 16 级奇数级输出波形的瞬态响应, 每次触控侦测时间长度为 $200 \mu \mathrm{s}$. 新 栅极驱动电路输出的显示扫描波形完整, 连续; 且触控侦测前后显示扫描波形无畸变. 这说明新的栅极 驱动电路能够实现一帧时间内多次触控侦测, 适用于 in-cell 型触控显示屏. 由于触控侦测可在显示面 


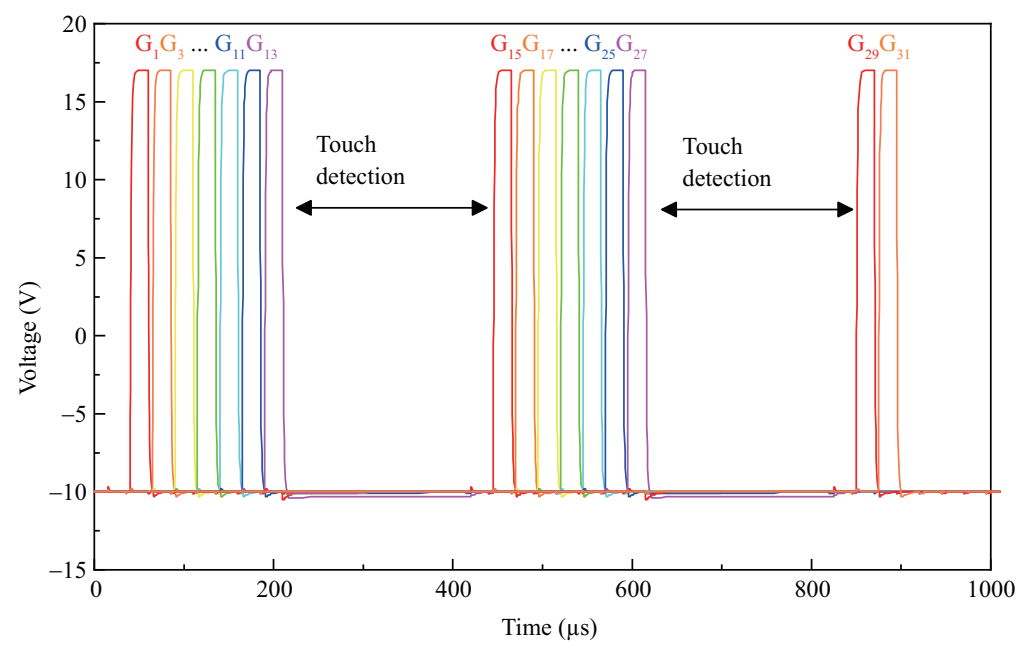

图 11 (网络版彩图) 新栅极驱动电路奇数级的瞬态响应 (第 1 级到第 16 级的显示/触控扫描输出)

Figure 11 (Color online) The simulated transient response from the 1st stage to the 16th stage of odd side of the proposed gate driver circuit

板内任意栅极扫描位置处触发, 该栅极驱动电路支持高触控侦测频率 in-cell 触控屏.

\section{4 结论}

本文提出了一种用于 in-cell 型电容触控屏的栅极驱动电路. 通过两级预充电结构存储、转移触控 侦测阶段的“再启动电荷”, 该新型集成栅极电路解决了驱动 TFT 的阈值电压漂移差异以及 “再启动 电荷” 泄漏问题. Eldo 分析结果表明, 新的栅极驱动电路可以抑制“再启动电荷”在触控侦测阶段的 损失量, 使得邻近级栅极驱动电路的输出波形上升/下降时间差异量小于 $1.6 \%$. 即使关键 TFT 的阈 值电压正向漂移 $10 \mathrm{~V}$, 电路的驱动能力几乎保持恒定, 输出波形的上升/下降时间的变化量仍然小于 2.4\%. 因此, 本文提出的栅极驱动电路稳定性较好, 适用于高触控侦测帧率的 in-cell 型电容触控屏.

\section{参考文献}

1 Tomita S, Okada T, Takahashi H. An in-cell capacitive touch sensor integrated in an LTPS WSVGA TFT-LCD. Jnl Soc Inf Disp, 2012, 20: 441-449

2 Tai Y T, Pearn W L, Huang K B, et al. Capability assessment for weibull in-cell touch panel manufacturing processes with variance change. IEEE Trans Semicond Manuf, 2014, 27: 184-191

3 Kim H, Min B W. Pseudo random pulse driven advanced in-cell touch screen panel for spectrum spread electromagnetic interference. IEEE Sens J, 2018, 18: 3669-3676

4 Kim C, Lee D S, Kim J H, et al. Advanced in-cell touch technology for large sized liquid crystal displays. In: Proceedings of SID Symposium Digest of Technology Papers, San Jose, 2015. 895-898

5 Moon S H, Haruhisa I, Kim K, et al. Highly robust integrated gate-driver for in-cell touch TFT-LCD driven in time division driving method. J Disp Technol, 2016, 12: 435-441

6 Chu L W, Liu P T, Ker M D. Design of integrated gate driver with threshold voltage drop cancellation in amorphous silicon technology for TFT-LCD application. J Disp Technol, 2011, 7: 657-664

$7 \mathrm{Hu}$ Z J, Liao C W, Li W J, et al. Integrated a-Si:H gate driver with low-level holding TFTs biased under bipolar pulses. IEEE Trans Electron Devices, 2015, 62: 4044-4050

8 Liao $\mathrm{C} \mathrm{W}$, He C D, Chen T, et al. Implementation of an a-Si:H TFT gate driver using a five-transistor integrated approach. IEEE Trans Electron Devices, 2012, 59: 2142-2148 
9 Zheng G T, Liu P T, Wu M C, et al. Design of bidirectional and low power consumption gate driver in amorphous silicon technology for TFT-LCD application. J Disp Technol, 2013, 9: 91-99

10 Liao C W, Hu Z J, Dai D, et al. A compact bi-direction scannable a-Si:H TFT gate driver. J Disp Technol, 2015, 11: $3-5$

11 Lin C L, Tu C D, Wu C E, et al. Low-power gate driver circuit for TFT-LCD application. IEEE Trans Electron Devices, 2012, 59: 1410-1415

12 Lin C L, Cheng M H, Tu C D, et al. Low-power a-Si:H gate driver circuit with threshold-voltage-shift recovery and synchronously controlled pull-down scheme. IEEE Trans Electron Devices, 2015, 62: 136-142

13 Chen F H, Chang C H, Tu C D, et al. Simple gate driver circuit with inserted stage for in-cell touch TFT-LCD applications. In: Proceedings of SID Symposium Digest of Technical Papers, Los Angeles, 2017. 105-107

14 Lin C L, Wu C E, Lee C E, et al. Insertion of simple structure between gate driver circuits to prevent stress degradation in in-cell touch panel using multi-V blanking method. J Disp Technol, 2016, 12: 1040-1042

\title{
A gate driver circuit with the two-stage pre-charge structure for in-cell touch panels
}

\author{
Shuai SHEN ${ }^{1,2}$, Congwei LIAO ${ }^{*}$, Jiwen YANG ${ }^{1} \&$ Shengdong ZHANG ${ }^{*}$ \\ 1. Shenzhen Graduate School, Peking University, Shenzhen 518055, China; \\ 2. Century Technology (Shenzhen) Corporation, Ltd., Shenzhen 518110, China \\ * Corresponding author. E-mail: zhangsd@pku.edu.cn, liaocw@pku.edu.cn
}

\begin{abstract}
Due to the charge leakage during the touch sensing period and the threshold voltage shift of the driving thin-film transistors (TFTs), the conventional gate driver circuits suffer from poor stability for in-cell touch displays with an increased touch reporting rate. This paper shows a new gate driver circuit, consisting of a two-stage pre-charge structure, which can reduce the charge leakage during the touch sensing period and suppress the threshold voltage shift of the driving TFTs. Simulation results demonstrate that, the rising and falling time differences between adjacent stages are $9.3 \%$ and $1.6 \%$ for the conventional and the proposed gate driver circuit, respectively. In the case that the threshold voltage of key TFT shifts by $+10 \mathrm{~V}$, the rising and falling time degradation ratios are $120 \%$ and $2.4 \%$ for the conventional and the proposed gate driver circuit, respectively. Therefore, the proposed gate driver circuit is stable for in-cell touch panels with a high touch reporting rate.
\end{abstract}

Keywords in-cell touch panel, gate driver on array (GOA), stability, a-Si:H, thin-film transistors (TFTs), time division driving method (TDDM)

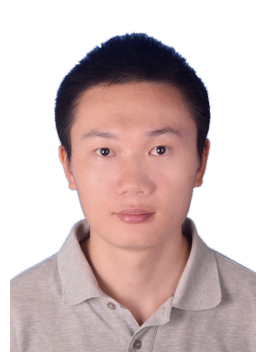

Shuai SHEN was born in 1990. He is currently pursuing a master's degree with the School of Electronics Engineering and Computer Science, Peking University Shenzhen Graduate School, Shenzhen, China. His primary research interests include integrated circuit designing for displays based on thin-film transistors.

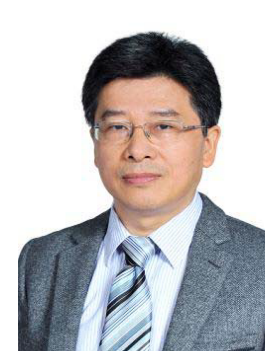

Shengdong ZHANG was born in 1964. He received his Ph.D. degree in electrical and electronic engineering from Peking University, Beijing, China. $\mathrm{He}$ has been with Peking University since 2002, where he is currently a full professor with the School of Electronics Engineering and Computer Science. His current research interests include thin film transistor technology and ICs for system on panel. 